\title{
ARRANJOS ESPACIAIS PARA A CULTURA DO FEIJOEIRO EM SISTEMA DE SEMEADURA CONVENCIONAL
}

\author{
SPATIAL ARRANGEMENTS FOR DRY BEAN \\ AT CONVENTIONAL CROP SYSTEM
}

\author{
José Antonio SCHAMNE ${ }^{1}$ \\ Pedro RONZELLI JÚNIOR ${ }^{2}$ \\ Edelclaiton DAROS ${ }^{3}$ \\ Henrique Soares KOEHLER ${ }^{4}$
}

\begin{abstract}
RESUMO
Com o objetivo de determinar o arranjo espacial mais adequado para o feijoeiro, em sistema de semeadura convencional, realizou-se um experimento na Estação Experimental do Cangüiri, da Universidade Federal do Paraná, no período de 13/01 a 18/04/2000 (cultivo das secas), utilizando a variedade 'FT Bionobre'. O delineamento experimental foi o de blocos ao acaso, com quatro tratamentos (espaçamentos de 0,30 m, 0,40 m, 0,50 m e 0,60 m, entre fileiras) arranjados em faixas e seis repetições para avaliação do rendimento e seus componentes, bem como do índice de colheita aparente. Para as avaliações das características morfológicas os tratamentos foram formados por parcelas subdivididas nos estádios de desenvolvimento $V_{4}, R_{6}, R_{7}$, $R_{8}$ e $R_{9}$. Cada parcela foi composta de dez fileiras de semeadura com 5,0 m de comprimento. A população foi padronizada nos quatro espaçamentos, pelo desbaste, ficando com média de 8,1 ; 10,$8 ; 13,5$ e 16,2 plantas. $\mathrm{m}^{-1}$. Verificou-se que, com o aumento do espaçamento entre fileiras, houve tendência de redução do índice de colheita aparente e de aumento na área foliar. A maior área foliar pode ter contribuído para a redução do rendimento em razão da baixa disponibilidade hídrica. O rendimento das plantas, no espaçamento de $0,30 \mathrm{~m}$ foi superior ao do espaçamento de $0,60 \mathrm{~m}$.

Palavras chave: Phaseolus vulgaris, espaçamento, população, morfologia, rendimento.
\end{abstract}

\begin{abstract}
A field trial was carried out at Cangüiri Experimental Station of The Universidade Federal do Paraná from January, $13^{\text {th }}$ till April, $18^{\text {th }}$ 2000. The objective was to determine the most adequated spatial arrangement for dry beans in conventional crop system. The variety used was 'FT Bionobre'. The experimental design was a randomized complete block, with four treatments $(0.30 \mathrm{~m}, 0.40 \mathrm{~m}, 0.50 \mathrm{~m}$ and $0.60 \mathrm{~m}$ row width) arranged in strips and six replications. There were evaluated: yield, grain weight, seeds per pod and apparent harvest index. In order to evaluate the morphological characteristics, a randomized complete block for width row, with developmental stages $V_{4}, R_{6}, R_{7}, R_{8}$ and $R_{9}$ split plot on it, was used. Plots were formed by ten rows with $5.0 \mathrm{~m}$ length. Populations were standardized by thinning in the four width rows, in which remained about 8.1; 10.8; 13.5; and 16.2 plants. $m^{-1}$. Tendency of leaf area increasing and apparent harvest index decreasing was observed when row width was increased. Greater leaf area associated with low water availability can have contributed to diminish the yield. Yield in $0.30 \mathrm{~m}$ row width was greater than the yield in $0.60 \mathrm{~m}$.
\end{abstract}

Key words: Phaseolus vulgaris, row width, population, morphology, yield.

\footnotetext{
${ }^{1}$ Engenheiro Agrônomo, M.Sc., Doutorando em Agronomia - Produção Vegetal na Universidade Federal do Paraná. Email: jaschamne@hotmail.com. „- Autor para correspondência.

2 Engenheiro Agrönomo, Doutor, Universidade Federal do Paraná, Professor Adjunto IV, Caixa Postal 19031, CEP 81531970, Curitiba, PR, Bolsista do CNPq. E-mail: agropri@ufpr.br.

${ }^{3}$ Engenheiro Agrônomo, Doutor, Universidade Federal do Paraná, Professor Adjunto IV.

${ }^{4}$ Engenheiro Florestal, Doutor, Universidade Federal do Paraná, Professor Adjunto IV.
} 


\section{INTRODUÇÃO}

A importância do arranjo espacial para o feijoeiro pôde ser verificada pelo aumento no rendimento da cultura, que ocorreu desde o momento em que os agricultores deixaram de semear em covas e passaram a distribuir o mesmo número de plantas em fileiras, de forma mais eqüidistante. Essa modificação no modelo de semeadura reduziu a competição entre plantas, especialmente quando havia estresse ambiental, fazendo com que fossem obtidos maiores rendimentos $[15,19]$.

Quando uma cultura é implantada, o espaçamento entre plantas permite que estas se desenvolvam adequadamente até o momento em que, com o crescimento, começam a competir entre si, ocorrendo alterações morfológicas e fisiológicas. Há remanejamento de fotoassimilados e alteração do surgimento e da senescência de folhas, flores e ramos, bem como influência no rendimento, que é resultado do número de plantas existentes na área pela produção individual destas [4]. A produção por planta depende do arranjo de sua população no campo e da plasticidade morfológica da espécie, que é fortemente influenciada por clima e genótipo [7].

O arranjo espacial das plantas na área de cultivo constitui fator preponderante na definição das relações de competição entre estas, influenciando a produtividade do feijoeiro $[5,10]$. Com o aumento do número de plantas por área existe distribuição diferenciada de luminosidade nos vários estratos do dossel vegetativo da cultura, proporcionando assim, alteração na utilização da energia solar. Sendo planta $\mathrm{C}_{3}$ o feijoeiro satura-se fotossinteticamente em intensidades de luz relativamente baixas [14]. A melhor distribuição da luz pode ser obtida mediante adequado arranjo das plantas, no qual as folhas inferiores recebam maiores taxas de iluminação, aumentando sua contribuição no processo fotossintético. Sendo assim, pode-se buscar maior produtividade por meio da utilização de arranjo espacial mais eqüidistante entre as plantas, fechando os espaçamentos entre as fileiras de semeadura e compensando com menor densidade na fileira. Esta modificação no modelo de semeadura pode resultar na obtenção de altas populações com menor número de plantas nas fileiras [5, 15].

A plasticidade de uma planta refere-se às características morfológicas individuais que os órgãos em desenvolvimento assumem, adaptandose às condições do ambiente específico de cultivo [4]. A plasticidade dos componentes de rendimento pode facilitar a manutenção de nível de produção estável quando a variação de um componente compensa a variação de outro [1].

Se uma população de plantas pode apresentar vários arranjos espaciais e estas podem diferir entre si em seu desenvolvimento morfológico, o que refletirá no rendimento, então haverá um arranjo mais adequado no qual o feijoeiro apresente desenvolvimento morfológico que the assegure maior rendimento. Assim, o objetivo geral do trabalho foi determinar o arranjo espacial mais adequado para o feijoeiro, variedade 'FT Bionobre', em sistema de semeadura convencional e os objetivos específicos foram analisar o rendimento do feijoeiro e seus componentes, bem como as características morfológicas das plantas.

\section{METODOLOGIA}

O experimento foi instalado no campo e conduzido no período do "cultivo das secas", de 13/01 a 18/04/2000, na área da Estação Experimental do Cangüiri (EEC), de propriedade da Universidade Federal do Paraná (UFPR), localizada no Município de Pinhais, Região Sudeste do Paraná, ao norte da Região Metropolitana de Curitiba, com altitude média de $925 \mathrm{~m}$ e coordenadas de $25^{\circ} 25^{\prime}$ de latitude Sul e $49^{\circ} 10^{\prime}$ de longitude Oeste. A região está localizada no Primeiro Planalto Paranaense e, segundo classificação de Köepen, apresenta clima tipo $\mathrm{Cfb}$. O solo é pertencente à unidade de mapeamento LATOSSOLO VERMELHO-AMARELO Distrófico típico, A proeminente, textura argilosa, fase campo subtropical e relevo suave ondulado.

O delineamento experimental utilizado foi o de blocos ao acaso, com quatro tratamentos (espaçamentos de $0,30 \mathrm{~m}, 0,40 \mathrm{~m}, 0,50 \mathrm{~m}$ e $0,60 \mathrm{~m}$ entre fileiras) arranjados em faixas e seis repetições para avaliação do rendimento, da massa média de 100 grãos, do número médio de grãos por vagem e do índice de colheita aparente. Para as demais avaliações os tratamentos foram formados por parcelas subdivididas nos estádios de desenvolvimento fisiológico $V_{4}, R_{6}, R_{7}, R_{8}$ e $R_{9}$, sendo o número de sub-parcelas variável, conforme as características analisadas. Cada parcela foi compostas por dez fileiras de semeadura, tendo $5,0 \mathrm{~m}$ de comprimento e largura de $3,0 \mathrm{~m}, 4,0 \mathrm{~m}$, $5,0 \mathrm{~m}$ e $6,0 \mathrm{~m}$, de acordo com os espaçamentos utilizados. A área total do experimento foi de $630 \mathrm{~m}^{2}$.

O experimento foi instalado em sistema de semeadura convencional, tendo como antecessora a cultura do milho, no verão, e pousio, no inverno. Foi utilizada a variedade 'FT Bionobre', Tipo II, porte ereto, que possui sementes com tegumento de cor preta fosca. A adubação foi a equivalente a $300 \mathrm{~kg} \cdot \mathrm{ha}^{-1}$ do formulado $\mathrm{N}-\mathrm{P}_{2} \mathrm{O}_{5}-\mathrm{K}_{2} \mathrm{O}$ 4-30-10. A semeadura foi feita no dia $13 / 01 / 2000$, sendo colocadas aproximadamente 25 sementes por metro. O estádio $V_{1}$ ocorreu no dia 17/01. O desbaste foi realizado no estádio $V_{3}, 17$ dias após a emergência (DAE), padronizando-se a população para 270 mil plantas.ha ${ }^{-1}$. Os espaçamentos de $0,30 \mathrm{~m}, 0,40 \mathrm{~m}, 0,50 \mathrm{~m}$ e $0,60 \mathrm{~m}$, entre fileiras, ficaram, em média, com $8,1,10,8,13,5$, e 16,2 plantas. $\mathrm{m}^{-1}$, respectivamente. A adubação de cobertura também foi realizada no estádio $V_{3}$, $20 \mathrm{DAE}$, sendo aplicado o equivalente a $50 \mathrm{~kg} \cdot \mathrm{ha}^{-1}$ de nitrogênio, na forma de uréia, que foi incorporada ao solo com enxada para evitar perdas por volatilização. O manejo fitossanitário foi realizado de 
acordo com as necessidades da cultura, mantendose a área dentro de padrões normais de controle de plantas daninhas, insetos e doenças.

As avaliações foram realizadas nos estádios de desenvolvimento fisiológico $V_{4}, R_{6}, R_{7}, R_{8}$ e $R_{9}$. A segunda e a oitava fileira foram utilizadas para as amostragens de dez plantas e as quatro linhas centrais para a avaliação do rendimento, sendo que em todas se desprezou $0,50 \mathrm{~m}$ nas extremidades, como bordaduras.

Nos estádios de desenvolvimento $V_{4}, R_{6}, R_{7}$ e $R_{8}$, foram realizadas as seguintes avaliações, em amostras de dez plantas: estatura e diâmetro do caule; número e comprimento de ramos; número de vagens no caule e nos ramos; massa seca total e de vagens; e área foliar, determinada com integrador automático.

A colheita foi realizada quando a cultura estava no estádio de desenvolvimento fisiológico $R_{9}$ $92 \mathrm{DAE})$. Nesta última etapa foram realizadas as seguintes avaliações na amostra de dez plantas: estatura e diâmetro do caule; número e comprimento de ramos; número de vagens no caule e nos ramos; número de grãos; massa média de 100 grãos, obtida pela média de três amostras; e índice de colheita aparente (ICa), calculado pela fórmula:

$$
\mathrm{ICa}=\frac{\text { massa seca dos grãos }}{\text { massa seca da parte aérea }} \times 100
$$

$\mathrm{Na}$ área útil de cada parcela foram feitas as seguintes avaliações: massa de grãos, para obtenção do rendimento equivalente em kg.ha-1; e umidade da massa de grãos, para correção do rendimento em kg.ha-1 para $13 \%$ de umidade relativa.

Os resultados foram submetidos à análise estatística, verificando-se primeiramente a homogeneidade de variâncias, pelo teste de Bartlett. As variáveis cujas variâncias se mostraram homogêneas tiveram seus tratamentos analisados por meio do teste F. Quando este revelou existirem diferenças estatisticamente significativas entre médias de tratamentos, estas foram comparadas pelo teste de Tukey a $5 \%$ de probabilidade $[9,18]$.

\section{RESULTADOS E DISCUSSÃO}

Durante todo o ciclo da cultura do feijoeiro houve precipitação de $188,2 \mathrm{~mm}$, quantidade bastante menor que os $300 \mathrm{~mm}$ tidos como necessários para produção normal da cultura [6]. No início do desenvolvimento da cultura essa baixa precipitação restringiu o porte dos feijoeiros, enquanto que nos períodos críticos em que o rendimento é definido (floração, formação e enchimento de vagens) $[6,14]$, tal condição limitou a produtividade. A temperatura oscilou entre $11,6^{\circ} \mathrm{C}$ e $30,9^{\circ} \mathrm{C}$, não havendo problemas com extremos [6, 14].

Embora no estádio $R_{9}$ todas as plantas apresentassem igual estatura, houve diferenças durante o desenvolvimento das mesmas. Os resultados apresentados na Tabela 1 confirmam que não há efeito significativo de diferentes espaçamentos na estatura de plantas no momento da colheita [7]. No entanto, contrariam resultados em que se verificou maior estatura de plantas com aumento do espaçamento $[8,12,17]$. Observa-se que a estatura do feijoeiro foi relativamente baixa. Isto ocorreu em razão da redução no comprimento dos entrenós, possivelmente, conseqüência da baixa precipitação ocorrida no período de desenvolvimento vegetativo.

TABELA 1 - Estatura e diâmetro do caule do feijoeiro, variedade 'FT Bionobre', em quatro espaçamentos e diferentes estádios de desenvolvimento, EEC/UFPR, Pinhais, PR, 2000

\begin{tabular}{|c|c|c|c|c|c|c|}
\hline \multirow{2}{*}{ Variável } & \multirow{2}{*}{$\begin{array}{c}\text { Espaçamento } \\
(\mathrm{m})\end{array}$} & \multicolumn{5}{|c|}{ ESTÁDIOS DE DESENVOLVIMENTO ${ }^{1}$} \\
\hline & & $\mathrm{V}_{4}$ & $\mathrm{R}_{6}$ & $\mathrm{R}_{7}$ & $\mathrm{R}_{8}$ & $\mathrm{R}_{9}$ \\
\hline \multirow{4}{*}{$\begin{array}{l}\text { Estatura } \\
(\mathrm{cm})\end{array}$} & 0,30 & $14,8 \mathrm{~d} A$ & 31,1 c A & 39,2 b B & 47,7 a $A$ & 47,7 a $A$ \\
\hline & 0,40 & 16,6 b A & 37,1 a $A$ & 44,6 a $A B$ & 40,3 a $B$ & 41,0 a $A$ \\
\hline & 0,50 & $20,0 \subset A$ & 37,4 b A & 47,4 a $A$ & 50,3 a $A$ & 45,7 a $A$ \\
\hline & 0,60 & 15,7 с A & 31,9 b A & 47,7 a $A$ & 51,8 a $A$ & 47,1 a $A$ \\
\hline \multirow{4}{*}{$\begin{array}{l}\text { Diâmetro } \\
\qquad(\mathrm{cm})\end{array}$} & 0,30 & 0,40 ab A & 0,38 b B & 0,43 ab $A$ & 0,44 a B & $0,43 a b \mathrm{~A}$ \\
\hline & 0,40 & $0,44 a b A$ & 0,48 a $A$ & 0,47 a $A$ & 0,40 b B & 0,40 b $A$ \\
\hline & 0,50 & 0,44 a $A$ & 0,37 b B & 0,46 a $A$ & 0,44 a B & 0,42 a $A$ \\
\hline & 0,60 & $0,44 \mathrm{~b} \quad \mathrm{~A}$ & 0,37 c B & $0,44 \mathrm{~b} \quad \mathrm{~A}$ & 0,52 a $A$ & 0,41 bc $A$ \\
\hline
\end{tabular}

Médias seguidas pela mesma letra, minúscula na horizontal e maiúscula na vertical, não diferem estatisticamente pelo teste de Tukey a $5 \%$ de probabilidade.

O diâmetro médio do caule das plantas não mostrou grandes diferenças entre os estádios, isso indica que seu desenvolvimento ocorreu até a planta atingir $\mathrm{o}$ estádio $\mathrm{V}_{4}$. Entre os espaçamentos os valores foram muito semelhantes, apesar de existirem diferenças estatisticamente significativas em alguns estádios. Embora essa característica seja influenciada pela população [17], os diferentes arranjos não a influenciaram. O diâmetro do caule foi suficiente para suportar o feijoeiro pois, apesar de o acamamento não ter sido avaliado quantitativamente, visualmente as plantas 
apresentaram-se eretas em todos os tratamentos.

O número de ramos, apresentado na Tabela 2, não foi diferente entre os espaçamentos, do estádio $R_{7}$ ao $R_{9} e$, no estádio $V_{4}$, tinha valor já praticamente definido. A semelhança no número de ramos entre os diferentes arranjos espaciais pode ser explicado pelo hábito de crescimento Tipo II da variedade 'FT Bionobre', que apresenta baixa variação desta característica, em diferentes condições ambientais [2, 11]. O mesmo não ocorreu, no entanto, com o comprimento de cada ramo. As plantas dos espaçamentos de $0,30 \mathrm{~m}$ e de $0,60 \mathrm{~m}$ apresentaram os maiores valores nos estádios $R_{8}$ e $R_{9}$. O maior comprimento de ramos do feijoeiro no espaçamento de $0,30 \mathrm{~m}$ pode ser explicado pela distribuição mais eqüidistante das plantas. No espaçamento de $0,60 \mathrm{~m}$ a proximidade entre as plantas dentro da fileira, associada à distância entre as fileiras, pode ter causado aumento no comprimento dos ramos lateralmente, na competição por luminosidade.

TABELA 2 - Número de ramos e comprimento médio de ramos do feijoeiro, variedade 'FT BIONOBRE', em quatro espaçamentos e diferentes estádios de desenvolvimento, EEC/UFPR, Pinhais, PR, 2000

\begin{tabular}{|c|c|c|c|c|c|c|}
\hline \multirow{2}{*}{ Variável } & \multirow{2}{*}{$\begin{array}{c}\text { Espaçamento } \\
(\mathrm{m})\end{array}$} & \multicolumn{5}{|c|}{ 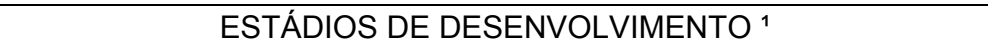 } \\
\hline & & $\mathrm{V}_{4}$ & $\mathrm{R}_{6}$ & $\mathrm{R}_{7}$ & $\mathrm{R}_{8}$ & $\mathrm{R}_{9}$ \\
\hline \multirow{4}{*}{$\begin{array}{l}\text { Número de } \\
\text { Ramos }\end{array}$} & 0,30 & 2,0 b $\quad B$ & $2,4 a b C$ & 2,9 a $A$ & $2,2 a b A$ & 2,3 ab $A$ \\
\hline & 0,40 & 3,0 b $A$ & 4,0 a $A$ & 3,3 ab A & $2,0 \subset A$ & 2,8 bc $A$ \\
\hline & 0,50 & 2,6 ab $A B$ & 3,2 a $\mathrm{B}$ & $2,8 \mathrm{ab} A$ & 2,0 b $A$ & 2,2 b $A$ \\
\hline & 0,60 & 2,5 a $A B$ & 2,7 a $B C$ & 2,8 a $A$ & 2,7 a $A$ & 2,5 a $A$ \\
\hline \multirow{4}{*}{$\begin{array}{l}\text { Comprimento } \\
\text { de Ramos }{ }^{1} \\
(\mathrm{~cm})\end{array}$} & 0,30 & $2,3 \mathrm{~d} A$ & 9,1 c A & 13,2 b A & 20,5 a $\mathrm{A}$ & 19,6 a $A B$ \\
\hline & 0,40 & $2,6 \subset A$ & 8,2 b A & 12,3 a $A$ & 13,3 a $B$ & 14,4 a $C$ \\
\hline & 0,50 & 3,2 с $A$ & 7,8 b A & 13,3 a $A$ & 14,8 a B & 16,7 a $B C$ \\
\hline & 0,60 & $2,8 \mathrm{~d} \mathrm{~A}$ & $8,2 \subset A$ & 14,8 b A & 22,3 a $A$ & 20,8 a $A$ \\
\hline
\end{tabular}

Médias seguidas pela mesma letra,minúscula na horizontal e maiúscula na vertical,não diferem estatisticamente pelo teste de Tukey a $5 \%$ de probabilidade.

2 Comprimento de todos os ramos dividido pelo número de ramos

Analisando os dados de área foliar apresentados na Tabela 3, observa-se que as plantas dos espaçamentos de $0,40 \mathrm{~m}$ e $0,50 \mathrm{~m}$ tiveram maior área foliar no estádio $\mathrm{V}_{4}$, apresentando, no entanto, os menores valores no estádio $R_{8}$, em razão do início antecipado do processo de abscisão.
O espaçamento de $0,30 \mathrm{~m}$, apesar de ser o que apresentou o menor valor no estádio $V_{4}$, foi $o$ único a apresentar incremento na área foliar até o estádio $R_{8}$. No estádio $R_{7}$ não foram verificadas diferenças significativas entre os espaçamentos. Esses resultados mostraram que houve diferença apenas quanto ao desenvolvimento da área foliar.

TABELA 3 - Área foliar do feijoeiro, variedade 'FT Bionobre', em quatro espaçamentos e diferentes estádios de desenvolvimento, EEC/UFPR, Pinhais, PR, 2000

\begin{tabular}{|c|c|c|c|c|c|}
\hline \multirow{2}{*}{ Variável } & \multirow{2}{*}{$\begin{array}{l}\text { Espaçamento } \\
\text { (m) }\end{array}$} & \multicolumn{4}{|c|}{ ESTÁDIOS DE DESENVOLVIMENTO ${ }^{1}$} \\
\hline & & $\mathrm{V}_{4}$ & $\mathrm{R}_{6}$ & $\mathrm{R}_{7}$ & $\mathrm{R}_{8}$ \\
\hline \multirow{4}{*}{$\begin{array}{l}\text { Área Foliar } \\
\qquad\left(\mathrm{mm}^{2}\right)\end{array}$} & 0,30 & 20.470 c B & 47.780 b B & 61.740 a $A$ & 69.550 a $A$ \\
\hline & 0,40 & 30.950 b AB & 67.310 a $A$ & 69.440 a $A$ & $37.560 \mathrm{~b} \mathrm{~B}$ \\
\hline & 0,50 & $34.000 \mathrm{~b} \mathrm{~A}$ & 59.270 a $A B$ & 65.010 a $A$ & $36.830 \mathrm{~b} \mathrm{~B}$ \\
\hline & 0,60 & 24.700 c $A B$ & 50.940 b B & 74.380 a $A$ & 67.220 a $A$ \\
\hline
\end{tabular}

$5 \%$ de probabilidade.

Observa-se, na Tabela 4, que o número médio de vagens no caule, no espaçamento de $0,50 \mathrm{~m}$, foi superior aos demais, no estádio $R_{7}$. No entanto, no estádio $R_{8}$, o maior valor foi observado no espaçamento de $0,60 \mathrm{~m}$. Em ambos os espaçamentos, houve queda de vagens, não sendo observadas diferenças significativas no número de vagens do caule do feijoeiro, no estádio $R_{9}$. A queda de vagens jovens (abortamento) ocorreu, provavelmente, em razão da baixa precipitação [14].
No estádio $R_{9}$, o número de vagens no caule representou aproximadamente $50 \%$ das vagens encontradas na planta.

Quanto ao número médio de vagens nos ramos, observa-se que no estádio $R_{8}$ os espaçamentos de $0,40 \mathrm{~m}$ e $0,50 \mathrm{~m}$ apresentaram os menores valores. Tal resultado não se confirma, entretanto, no estádio $R_{9}$, no qual as variações existentes entre os espaçamentos são pequenas. Com relação ao número médio de vagens por 
planta, observa-se que houve aumento nos espaçamentos de $0,30 \mathrm{~m}$ e $0,60 \mathrm{~m}$ até o estádio $R_{8}$. Já nos espaçamentos de $0,40 \mathrm{~m}$ e $0,50 \mathrm{~m}$, os maiores valores foram observados no estádio $R_{7}$. Não houve diferenças significativas no estádio $R_{9}$. $A$ competição entre plantas no espaçamento de $0,60 \mathrm{~m}$, que era o que apresentava maior número de plantas na fileira, possivelmente contribuiu para a alta redução no número de vagens do estádio $R_{8}$ para o $\mathrm{R}_{9}$.

TABELA 4 - Número de vagens no caule, nos ramos e total do feijoeiro, variedade 'FT Bionobre', em quatro espaçamentos e diferentes estádios de desenvolvimento, EEC/UFPR, Pinhais, PR, 2000

\begin{tabular}{|c|c|c|c|c|}
\hline \multirow{2}{*}{ Variável } & \multirow{2}{*}{$\begin{array}{c}\text { Espaçamento } \\
(\mathrm{m})\end{array}$} & \multicolumn{3}{|c|}{ ESTÁDIOS DE DESENVOLVIMENTO ${ }^{1}$} \\
\hline & & $\mathrm{R}_{7}$ & $\mathrm{R}_{8}$ & $\mathrm{R}_{9}$ \\
\hline \multirow{4}{*}{$\begin{array}{l}\text { Número Médio de } \\
\text { Vagens no Caule }\end{array}$} & 0,30 & 3,7 с C & 8,3 a $A$ & 6,0 b A \\
\hline & 0,40 & 6,7 a $A B$ & $6,2 a b B$ & 4,7 b $A$ \\
\hline & 0,50 & 8,4 a $A$ & 6,1 b $\quad B$ & 5,3 b A \\
\hline & 0,60 & 6,2 b B & 9,8 a $A$ & 5,4 b A \\
\hline \multirow{4}{*}{$\begin{array}{l}\text { Número Médio de } \\
\text { Vagens nos Ramos }\end{array}$} & 0,30 & 3,2 b C & 6,1 a $B$ & 6,0 a $A$ \\
\hline & 0,40 & 5,9 a $A B$ & 3,7 b C & 5,2 a $A B$ \\
\hline & 0,50 & 6,6 a $A$ & 4,1 b C & 4,4 b B \\
\hline & 0,60 & 5,1 b B & 8,0 a $A$ & 5,3 b $A B$ \\
\hline \multirow{4}{*}{$\begin{array}{l}\text { Número Médio de } \\
\text { Vagens na Planta }\end{array}$} & 0,30 & 7,0 с C & 14,4 a $B$ & 12,0 b A \\
\hline & 0,40 & 12,6 a $A B$ & 9,9 b C & 9,9 b A \\
\hline & 0,50 & 15,0 a $A$ & 10,2 b C & 9,7 b $A$ \\
\hline & 0,60 & 11,3 b $B$ & 17,8 a $A$ & 10,6 b A \\
\hline
\end{tabular}
de probabilidade.

O hábito de crescimento da variedade utilizada foi fator importante para que não ocorressem diferenças significativas no momento da colheita, porque a plasticidade do feijoeiro Tipo II tende a ser relativamente baixa [4]. Assim, foram observadas poucas diferenças no número de vagens dos ramos e, conseqüentemente, no número total de vagens.
A massa seca das vagens, apresentada na Tabela 5, mostrou seus maiores valores no estádio $R_{8}$, tendo redução significativa no estádio $R_{9}$. Essa redução ocorreu, provavelmente, em razão da baixa precipitação, que causou abortamento de vagens [14]. Assim, apesar de existirem diferenças entre os espaçamentos no estádio $R_{8}$, essas não ocorreram no estádio $R_{9}$.

TABELA 5 - Massa seca (MS) total e das vagens, em gramas, do feijoeiro, variedade 'FT Bionobre', em quatro espaçamentos e diferentes estádios de desenvolvimento, EEC/UFPR, Pinhais, PR, 2000

\begin{tabular}{|c|c|c|c|c|c|c|}
\hline \multirow{2}{*}{ Variável } & \multirow{2}{*}{$\begin{array}{c}\text { Espaçamento } \\
(\mathrm{m})\end{array}$} & \multicolumn{5}{|c|}{ 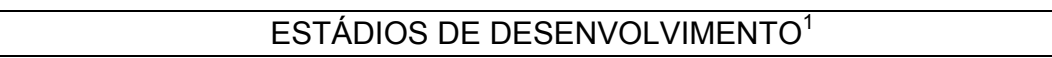 } \\
\hline & & $\mathrm{V}_{4}$ & $\mathrm{R}_{6}$ & $\mathrm{R}_{7}$ & $\mathrm{R}_{8}$ & $\mathrm{R}_{9}$ \\
\hline \multirow{4}{*}{$\begin{array}{l}\text { MS de } \\
\text { Vagens }\end{array}$} & 0,30 & & & 1,02 c B & 5,14 a $B$ & 3,17 b $A$ \\
\hline & 0,40 & & & 1,87 b $A B$ & 4,84 a $B$ & $2,62 \mathrm{~b} \mathrm{~A}$ \\
\hline & 0,50 & & & $2,50 \mathrm{~b} \mathrm{~A}$ & 6,49 a $A$ & 3,17 b A \\
\hline & 0,60 & & & 1,48 c B & 6,34 a $A$ & 2,88 b A \\
\hline \multirow{4}{*}{$\begin{array}{l}\text { MS } \\
\text { Total }\end{array}$} & 0,30 & 3,82 d $A$ & 7,90 с $A$ & 10,06 b $B$ & 15,54 a $B$ & $6,96 \subset A$ \\
\hline & 0,40 & 4,20 с $A$ & 8,74 b A & 11,56 a $A$ & 12,65 a $C$ & 6,04 C $A$ \\
\hline & 0,50 & 4,76 e $A$ & $8,34 \mathrm{c} \mathrm{A}$ & 12,11 b $A$ & 14,62 a $B$ & 6,77 d $A$ \\
\hline & 0,60 & 3,94 d A & 7,65 с A & 11,66 b A & 17,31 a $A$ & 6,77 с A \\
\hline
\end{tabular}

Médias seguidas pela mesma letra minúscula na horizontal e maiúscula na vertical não diferem estatisticamente pelo teste de Tukey a $5 \%$ de probabilidade.

A massa seca total foi crescente em todos os espaçamentos até o estádio $R_{8}$. Não ocorreram diferenças entre a massa seca total nos diferentes espaçamentos nos estádio $V_{4}, R_{6}$ e $R_{9}$. No estádio $\mathrm{R}_{7}$, as plantas do espaçamento de $0,30 \mathrm{~m}$ apresentaram os menores valores, por terem menor massa seca de vagens nesse estádio. Isso indica que no espaçamento de $0,30 \mathrm{~m}$ ocorreu desenvolvimento mais lento das plantas, uma vez que há acentuado aumento no número e na massa seca de vagens do estádio $R_{7}$ para o $R_{8}$, bem como o aumento na área foliar. No estádio $R_{8} \quad 0$ 
espaçamento de 0,60 $\mathrm{m}$ teve maior massa seca e o espaçamento de $0,40 \mathrm{~m}$ apresentou o menor valor. Nesse estádio a principal causa das diferenças foi o início do processo de abscisão nas plantas dos espaçamentos de $0,40 \mathrm{~m}$ e $0,50 \mathrm{~m}$.

Observa-se na Tabela 6 que houve diferença significativa entre o rendimento no espaçamento de $0,30 \mathrm{~m}$ e no de $0,60 \mathrm{~m}$. Houve tendência de redução do rendimento com $\mathrm{o}$ aumento do espaçamento $(r=-0,95)$, contrariando um resultado [12], mas concordando com a afirmação de que há correlação inversa entre essas variáveis $[7,8,10$, $15,16]$. O maior rendimento no espaçamento de $0,30 \mathrm{~m}$ ocorreu, possivelmente, em razão da distribuição mais eqüidistante entre as plantas, o que resultou em menor competição entre estas.

Os componentes de rendimento não apresentaram diferenças significativas qualquer que fosse o espaçamento considerado. Dos componentes analisados o que apresentou menor variação foi a massa média de 100 grãos, o que confirma a afirmação de ser característica pouco influenciada pelo espaçamento [3, 10, 13]. Não foram observadas diferenças significativas entre os espaçamentos avaliados para o índice de colheita aparente. Entretanto, este apresentou tendência de redução $(r=-0,92)$ com o aumento do espaçamento. Isso significa que, proporcionalmente, maior quantidade de fotoassimilados foi destinada à formação de estruturas reprodutivas nos espaçamentos menores. Como não houve diferenças significativas entre a massa seca total das plantas, menor índice de colheita aparente significa redução no rendimento.

Analisando a área foliar (Tabela 3) no estádio $\mathrm{R}_{7}$, período em que não havia iniciado o processo de abscisão em nenhum tratamento, verifica-se que houve tendência de aumento deste valor nos espaçamentos maiores. A baixa precipitação aliada à maior área foliar representou alta taxa transpiratória, com excessiva perda de água. Essa condição pode ter prejudicado a translocação de carboidratos, com conseqüente redução do rendimento.

TABELA 6 - Número médio de vagens por planta (NMVP), número médio de grãos por vagem (NMGV), massa média de 100 grãos (MM100G), rendimento expresso em $\mathrm{kg}^{-h^{-1}}$ e corrigido para umidade de $13 \%$ e índice de colheita aparente (ICA) do feijoeiro, variedade 'FT Bionobre', no estádio R, EEC/UFPR, Pinhais, PR, 2000

\begin{tabular}{|c|c|c|c|c|c|}
\hline Espaçamento (m) & NMVP & NMGV & MM100G (g) & Rendimento $^{1}$ & ICA \\
\hline 0,30 & 12,0 & 3,2 & 20,65 & $1.419 \mathrm{~A}$ & 72,5 \\
\hline 0,40 & 9,9 & 3,1 & 20,05 & 1.290 & 73,7 \\
\hline 0,50 & 9,7 & 3,7 & 20,22 & $1.257 \mathrm{AB}$ & 63,0 \\
\hline 0,60 & 10,6 & 3,4 & 20,01 & $986 \quad \mathrm{~B}$ & 59,2 \\
\hline
\end{tabular}

\section{CONCLUSÕES}

1) Não há diferenças no número de ramos entre as plantas dos vários espaçamentos testados, em razão do hábito de crescimento da variedade 'FT Bionobre' ser do Tipo II.

2) Com o aumento do espaçamento, entre fileiras há tendência de aumento na área foliar.

3) A maior área foliar associada à baixa precipitação causa diminuição no rendimento.

4) Há tendência de redução do índice de colheita aparente com o aumento do espaçamento, reduzindo o rendimento.

5) Espaçamento eqüidistante entre as plantas aumenta o rendimento.

6) O espaçamento mais adequado a ser utilizado é de, no máximo, $0,50 \mathrm{~m}$ entre fileiras.

\section{REFERÊNCIAS}

[1] ADAMS, M. W. Basis of yield component compensation in crop plants with special reference to the bean, Phaseolus vulgaris. Crop Science, Madison, v.7, n.5, p. 505-510, 1967.

[2] ALCÂNTARA, J. P.; RAMALHO, M. A. P.; ABREU, A F. B.; SANTOS, J. B. Avaliação de cultivares de feijão (Phaseolus vulgaris L.) em diferentes densidades de semeadura e condições de ambiente. Ciência e Prática, Lavras, v.15, n.4, p. 375-384, 1991.

[3] ARF, O.; SÁ, M. E.; OKITA, C. S.; TIBA, M. A.; NETO, G. G.; OGASSAWARA, F. Y. Efeito de diferentes espaçamentos e densidades de semeadura sobre $\mathrm{O}$ desenvolvimento do feijoeiro (Phaseolus vulgaris L.). Pesquisa Agropecuária Brasileira, Brasília, v.31, n.9, p. 629-634, 1996.

[4] COSTA, J. G. C.; KOHASHI-SHIBATA, J.; COLIN, S. $M$. Plasticidade no feijoeiro comum. Pesquisa Agropecuária Brasileira, Brasília, v.18, n.2, p. 159$167,1983$.

[5] CROTHERS, S. E.; WESTERMANN, D. T. Plant population effects on the seed yield of Phaseolus vulgaris L. Agronomy Journal, Madison, v.68, n.6, p. 958-960, 1976.

[6] DOURADO NETO, D.; FANCELLI, A. L. Produção de feijão. Guaíba: Agropecuária, 2000. $386 \mathrm{p}$.

[7] FRONZA, V.; VIEIRA, C.; CARDOSO, A. A.; CRUZ, C. D. Resposta de cultivares eretos de feijão (Phaseolus vulgaris L.) a espaçamentos entre linhas e níveis de adubação. Revista Ceres, Viçosa, v.41, n.235, p. 317-326, 1994.

[8] FRONZA, V.; VIEIRA, C.; CARDOSO, A. A.; CRUZ, C. D.; PEREIRA, P. R. G. Resposta de cultivares eretos de feijão (Phaseolus vulgaris L.) a espaçamento entre linhas e níveis de adubação mineral. Revista Ceres, Viçosa, v.41, n.237, p. 567-583, 1994.

[9] GOMES, F. P. Curso de estatística experimental. 13 ed. Piracicaba: ESALQ, 1990. 468 p. 
[10]GRAFTON, K. F : SCHNEITER, A. A.; NAGLE, B. J. Row spacing, plant population, and genotype $X$ row spacing interaction effects on yield components of dry bean. Agronomy Journal, Madison, v.80, n.4, p. 631 $634,1988$.

[11]GUIDOLIN, A. F.; MEROTTO JUNIOR, A.; ENDER, M.; SAGONI, L.; DUARTE, I. A. Efeito do arranjo e da população de plantas sobre o crescimento do feijão em semeadura tardia. Ciência Rural, Santa Maria, v.28, n. 4, p. 547-551,1998.

[12]HORN, F. L.; SCHUCH, L. O.; SILVEIRA, E. P.; ANTUNES, I. F.; VIEIRA, J. C.; MARCHIORO, G.; MEDEIROS, D. F.; SCHWENGBER, J. E. Avaliação de espaçamento e populações de plantas de feijão visando à colheita mecanizada direta. Pesquisa Agropecuária Brasileira, Brasília, v.35, n.1, p. 41-46, 2000.

[13]KRINSKI, S. A.; SCHAMNE, J. A.; ABE, F. N. População de plantas para duas variedades de feijãocomum. In: REUNIÃO NACIONAL DE PESQUISA DE FEIJÃO, 6., Salvador, 1999. Resumos Expandidos. Santo Antônio de Goiás: Embrapa Arroz e Feijão. 1999. p. 699-701. (Embrapa Arroz e Feijão: Documentos 99).

[14]PORTES, T. A. Ecofisiologia. In: ZIMMERMANN, M. J. O.; ROCHA, M.; YAMADA, T. Cultura do feijoeiro: fatores que afetam a produtividade. Piracicaba, Associação Brasileira para Pesquisa da Potassa e do Fosfato, 1988. p. 101-137.
[15]ROCHA, J. A. M. Produção de feijoeiro (Phaseolus vulgaris L.) cultivado em populações variáveis quanto ao número e ao arranjamento de plantas. Piracicaba, 48 f: Dissertação (Mestrado em Agronomia - Produção Vegetal) Universidade Federal do Paranaá, 1991.

[16] SANDOVAL-AVILA, D. M.; MICHAELS, T. E.; MURPHY, S. D.; SWANTON, C. J. Effect of tillage and planting pattern on performance of white bean in Ontario. Canadian Journal of Plant Science, Ontario, p. 801-805.(Short Communication), 1994.

[17] SCHUCH, L. O. B.; ANTUNES, I. F.; SILVEIRA, E. O.; VIEIRA, J. C.; HORN, F. L.; MARCHIORO, G.; MEDEIROS, D. F. Resposta do feijoeiro à variação no espaçamento e população de plantas. In: REUNIÃO NACIONAL DE PESQUISA DE FEIJÃO, 4., Londrina, 1993. Resumos. Londrina: IAPAR, 1993. p. 43.

[18]STEEL, R. G. D.; TORRIE, J. H. Principles e procedures of statistics with special reference to the biological sciences. New York: McGrow-Hill Co., 1960. $481 \mathrm{p}$

[19]VIEIRA, C.; ALMEIDA, L. A. Experimento de espaçamento de semeadura do feijão (Phaseolus vulgaris). Revista Ceres, Viçosa, v.12, n.70, p. 219228,1965 .

Recebido para publicação em 14 MAR 2002 [SA 043/2001] Aceito para publicação em 15 JUL 2002 